\title{
Role of Liquid Tuned Mass Dampers in Improving Torsional Competence of Asymmetric Buildings
}

\author{
A Shruthi ${ }^{1}$ and Dr. N. Murali Krishna ${ }^{2}$ \\ ${ }^{1}$ Asst. Professor, CVR College of Engineering/Civil Engg. Department, Hyderabad, India \\ Email: shruthiarikeri95@gmail.com \\ ${ }^{2}$ Professor, CVR College of Engineering/Civil Engg. Department, Hyderabad, India \\ Email: nmuralikrishna1956@gmail.com
}

\begin{abstract}
The development of urban environment is reflected by the increase in tall structures. These structures are highly vulnerable of lateral forces caused by different kinds of natural calamities. To counter their effect on structures, many types of structural elements like shear walls, infill frames etc., are tried over a period of time. But, their inclusion is often unacceptable, besides the cost escalation. In this backdrop, tuned mass dampers are tried as the most viable the alternatives to shear walls. Many types of tuned mass damper systems are explored as on date. Currently, the concept of liquid tuned mass dampers as TMDs is attracting wide research interest as it is an integral part of structural system, go well with the architectural features of the building and do not cause much cost escalation. Modelling the overhead water tank in a building as liquid tuned mass dampers would significantly reduce the amplitude of vibration and the maximum base shear in a building when subjected lateral disturbances.
\end{abstract}

A Tuned Mass Damper (TMD) is a device consisting of a mass and spring that is attached to a structure in order to reduce the dynamic response of the structure. The frequency of the damper is tuned to a particular structural frequency so that when that frequency is excited, the damper will resonate out of phase with the structural motion. The Tuned Liquid Mass Damper (TLMD) is modeled with the help of overhead water tanks which form an integral part of the building. These tanks while serving the purpose of storing water, would also meet the requirements desirable of a tuned mass damper. The structural effectiveness of building with and without TLMD is presented by carrying-out the structural analysis using both Response Spectrum Method and Linear Time History Analysis. The performance of the tuned liquid mass dampers is demonstrated by comparing the values of Maximum Story Deflection and the magnitudes of Base shear of the building for different tank capacities. The study is proposed to be carried out on an RC building with plan asymmetry, located in a highly seismic active region using ETABS.

Index Terms: Tall structures, Tuned Mass Damper (TMD), Tuned Liquid Mass Damper (TLMD), Base shear, Water tank, Seismic vibrations.

\section{INTRODUCTION}

Urbanization of a metropolis is in general reflected by tall buildings all around and improvised infrastructure. For a structural designer, tall structures pose design challenges as they are highly vulnerable to natural calamities like Cyclones and Earthquakes. Even the man induced causes like blasts may pose severe threat to the high raised structures. On seismic front, the threat to structures is caused due to huge amount of lateral forces and lateral displacements. The above two reasons necessitate the provision of large sizes of column elements and very stiff structural configuration, which is not always acceptable.

To avert the undesirable effects caused by the lateral forces on structures, the shear walls are introduced in some of the bays of the building structures. Excessive use of shear walls in buildings is also not always acceptable as their placement infringes with the vehicular movement and the architectural features of the building. As the next alternative, the base isolators are tried at to reduce both base shear and the lateral displacements of the buildings. Though the idea appears to be acceptable, it is a costly proposition, hence it is not a desirable alternative. In this backdrop, introduction of Tuned Mass Dampers is considered the most effective alternative. The TMDs are both economical and are effective in reducing both base shear and amplitude of vibrations of the building subjected to dynamic causes. Amongst the Tuned Mass Dampers, the usage of Liquid Tuned Mass Dampers are more encouraged. Studies on Liquid Tuned Mass Dampers are the prime area of the present-day research activity. Since the overhead water tanks are integral part of a structure, they can serve as Tuned Liquid Mass Dampers and are considered a very costeffective solution in seismic design.

In the present study, the mass of water in the tank plus the mass of the water tank constitute the total mass of the Tuned Mass Damper. The stiffness of the columns of the water tank serves as stiffener of the Tuned Mass Damper. The structural damping due to the concrete structure constitutes the damping of the Tuned Mass Damper. By suitably altering the mass of liquid in the water tank, the size of the water tank and the number and size of the columns supporting the water tank, the mass, the damping and the stiffness of the Tuned Liquid Damper are tuned.

\section{A. Objective of the study}

The objective of the present study is to propose a suitable method to choose the size of the water tank and mass of the water tank with water to arrive at an optimal configuration of the Liquid Tuned Mass Damper. Such an arrangement should result in the lowest possible base shear and lateral displacement in the event of seismic disturbance to the building. 


\section{B. Procedure Adapted}

In the present study, a high-raised RCC building subjected to seismic activity is analyzed using Response Spectrum Method and Linear Time History analysis method using ETABS. For the purpose of this study, a G+10 storied building with asymmetric configuration located in Zone-III and Zone-IV of seismic disturbance is considered. The analysis is carried out with and without considering the effects of Liquid Tuned Mass Dampers. The study is carried-out on Rectangular, L-shaped, T-shaped and Ushaped buildings. The studies are repeated by varying the water level in tanks as empty, one-third full, two-third full and full water tank conditions.

\section{LITERATURE REVIEW}

Mudabbir Imran and B. K. Raghu Prasad had examined the effectiveness of both single and multiple Tuned Mass Dampers (TMDs) when subjected to various earthquake ground accelerations using ETABS. It was seen that MTMD with Non-uniform mass ratio was more efficient than MTMD with uniform mass ratio, but it cannot be economical [1].

Lucchini et al proposed a method for designing a TMD system for the seismic protection of a multi-storied buildings. It was found that with the increase of the total mass of the TMD system, its performance tends to improve, the building response reduces and becomes less sensitive to the uncertain parameter variations. Uncertainty in the properties of the ground excitation reduces robustness of the TMD system by increasing the variation of its performance. With the increase of the uncertainty level, it has been observed that period and damping of the TMD units increases [2].

S.M. Zahrai and A. Ghannadi-Asl had discussed the effectiveness of Tuned Mass Dampers (TMDs) to control the structures under earthquake excitations using tuned mass dampers for buildings with different number of storeys and heights. The results of time-history analysis were compared with those of a response spectrum analysis for the structures with and without TMD in order to judge its effectiveness. It was observed that TMD is effective in reducing maximum displacement in MRF buildings of Tabas earthquake and El Centro earthquake [3].

Ashish A. Mohite et. al. had carried out the analysis of the seismic behavior of different storeys of a building with tuned mass damper and without tuned mass damper by using ETABS. It was found that the TMDs can be successfully used to control vibration of the structure. For the regular building frame, TMD was found to effectively reduce top storey displacement. The reduction was found to be decreasing in a descending order from bottom storey to top storeys. With these results it was concluded that the TMD should be placed at top floor for the best control [4].

Saurabh Chalke and P.V. Muley had discussed the vibration control of the framed structure using tuned mass damper by using ETABS 2015 by analyzing a G+51 storied structure without damper and with tuned mass damper and compared the displacement and drift values under the dynamic condition. It was concluded that the values of displacement and drift were found to be more on structure when acted upon by dynamic conditions without damper. By assigning Tuned Mass Damper to the structure, it was found to be more stable as the values of displacement and drift were reduced and the acceleration also been reduced significantly using tuned mass damper [5].

Rajashekhar S. Talikoti et. al. had studied the effectiveness of TMD in controlling the vibrations of structure. A building structure was modelled with and without TMD and Response spectrum analysis was carriedout. From the study, it was found that TMD was more effective when it is attached at the top floor of building and the presence of TMD resulted in gradual decrement of the displacement, the storey drift and the fundamental period of the structure [6].

Manjusha M had carried out the analytical investigation to study the feasibility of implementing water tank as a passive Tuned Mass Damper (TMD) using ETABS 2015. Multistorey concrete building structure was taken for the study and a water tank was placed on the roof. The mass and frequency of both were tuned to the optimized values. The behavior of the tank under full and empty tank condition subjected to earthquake data was studied. It was concluded that TMD had effectively reduced the overall behavior of the structure resulting in economic and safe design and can successfully be used to control the response of the structure [7].

M.J Tait et. al. investigated the performance of unidirectional and bidirectional Tuned Liquid Dampers (TLDs) under random excitation. A series of experiments were carried-out on scale model structure-tuned liquid damper systems to evaluate their performance. The results are compared with that of a well-known tuned mass damper. This study has resulted in the development of performance charts for a tuned liquid damper. These charts allowed the efficiency of a tuned liquid damper to be examined for a number of varying parameters, which included the excitation amplitude, water depth and building frequency. It was concluded that a TLD is efficient and robust to reduce dynamic structural motions that occur as a result of random excitation [8].

Chidige Anil Kumar and E Arunakanthi analyzed the feasibility of implementing water tank as passive TMD and found the optimum level of water which would reduce peak response of the structure subjected to seismic forces using SAP2000 by considering a three and seven storeyed building designed for gravity and seismic using 1893:2002. Influence of TLD was found to be effective and the model study showed encouraging results for Bhuj earth quake data. It was found that the roof displacements, story drifts, time period and base shear have been reduced for $2 / 3$ level of water tank model compared to other levels concluding $2 / 3^{\text {rd }}$ 
level as the optimum level of water to be maintained for effective results. It was concluded by them that if the level of water in the tank is maintained between half full to two thirds full (having mass ratio 25\%) there is a tendency to mitigate the vibrations of RC frame structures under seismic excitations [9].

\section{Methodology}

The dynamic analysis of the building is carried out using Response Spectrum method and Linear Time History method corresponding to seismic Zone-III and IV of seismic activities.

Modelling of structure using TLD is as follows:

1." A three-dimensional model of $\mathrm{G}+10$ storied building structure is created using ETABS.

2." Creating and assigning Material properties.

3." Creating and assigning Section properties.

4." Response spectrum and Time history functions are defined for the desired zones considered in the study.

5." Assigning the external and internal wall loads acting on the structure wherever necessary.

6." Assigning the floor finish load and live load acting on slab panels.

7." A water tank is created at the desired location on the topmost floor of the existing building structure.

8." The water tank with desired length, width and height are created and the beam, column and slab properties are assigned.

9." The next step is modelling a Tuned Liquid Damper which is attached to the water tank of the same building.

10." A TLD is modelled in ETABS using a combination of 'Linear link type' and a 'Point spring' attached in series.

11." From Define $\rightarrow$ Section properties $\rightarrow$ Link/support properties, add a new link property by selecting the 'Linear link type'. The directional properties U1, U2, and $\mathrm{U} 3$ are selected in which $\mathrm{U} 3$ type is fixed.

12." From Properties option $\rightarrow$ modify/show all $\rightarrow$ the stiffness and damping values for U1, U2 directions are entered.

13." Mass and weight of the TLD (the water) is entered, which is the load acting on the water tank or the weight of water present in the water tank. In this step, the water level is varied to effect the changes in the values of mass and weight of TLD and changes are affected in the stiffness and damping as well.

14." Define $\rightarrow$ Spring properties $\rightarrow$ Point springs $\rightarrow$ Add new spring, select the 'User specified/link properties option'.

15." From the 'single joint links at point' dialogue box, add the previously defined link property and the axial direction ' $+\mathrm{z}$ ' selected.

16." Links are drawn using 'draw link' option.

17." The links are connected to the columns in ' $+\mathrm{z}$ ' direction (upward), along which the water tank is standing.

18." The point spring which is defined earlier is assigned to the joints at the base of the water tank by using 'Draw springs' option.

19." The mass of the TLD is assigned towards the free end of the link by selecting the joints of water tank, where springs and links are connected.
20." From the command Assign $\rightarrow$ Joint loads, the load value is assigned in downward or ' $-z$ ' direction. The total load acting on the water tank is divided equally on to the number of columns on which it is standing as shown in Figure 1.

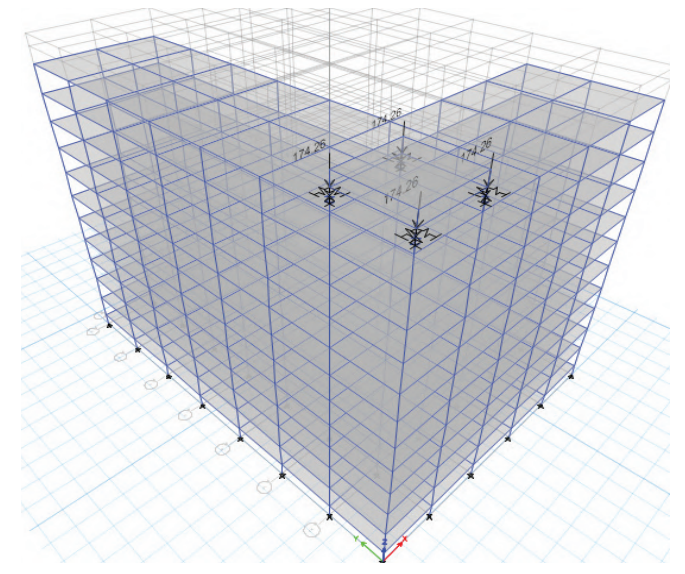

Figure 1. Plan with Joint loads in ETABS

The buildings considered for the study are RC ordinary moment resisting space frames of $\mathrm{G}+10$ storied located in Zone III and Zone IV of seismic disturbances. The analysis is carried-out on a rectangular shaped building and three different asymmetric shaped buildings of plan shapes L, T and $U$. The layout plan is such that each one of the bays is $6 \mathrm{~m}$ long. The study is conducted by varying the water level in water tank by considering 1 . Empty water tank, 2. Onethird full, 3. Two-third's full and 4. Full water tank conditions using ETABS.

The Plan configuration consists of

1." Model 1 - L-shaped Building plan (Figure 2),

2." Model 2 - T-shaped Building plan (Figure 3),

3." Model 3 - U-shaped Building plan (Figure 4),

4." Model 4 - Rectangular Building plan (Figure 5),
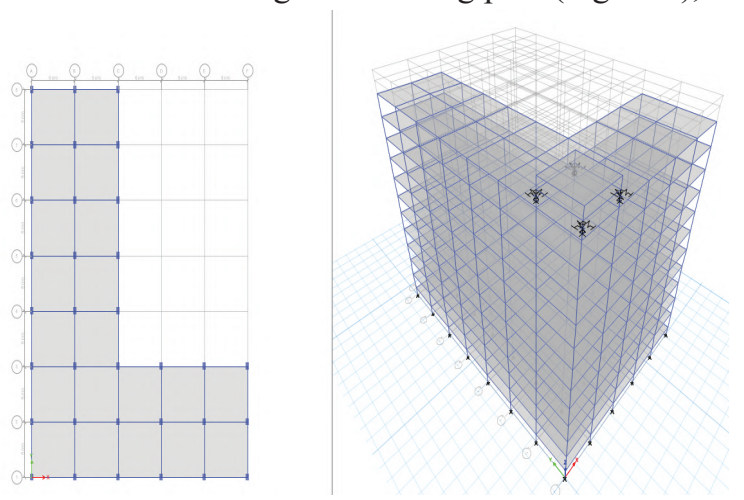

Figure 2. Plan and Isometric view of Model-1 with TLD 

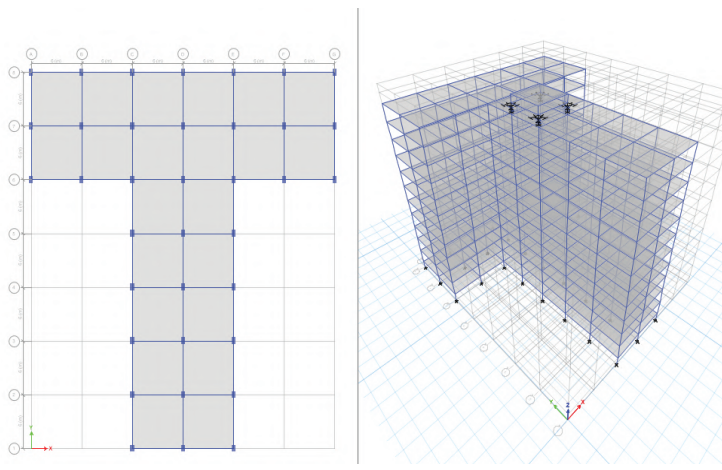

Figure 3. Plan and Isometric view of Model-2 with TLD
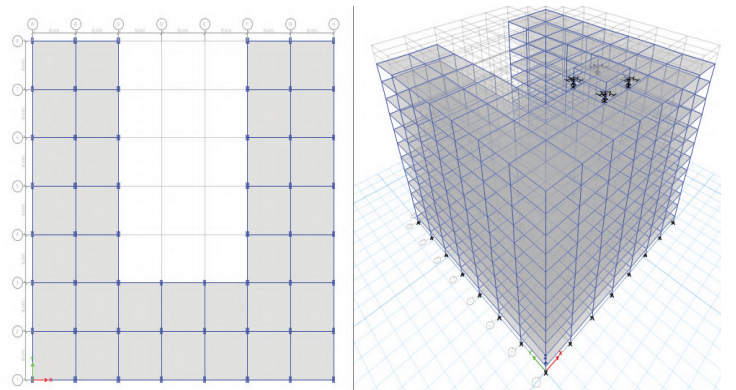

Figure 4. Plan and Isometric view of Model-3 with TLD
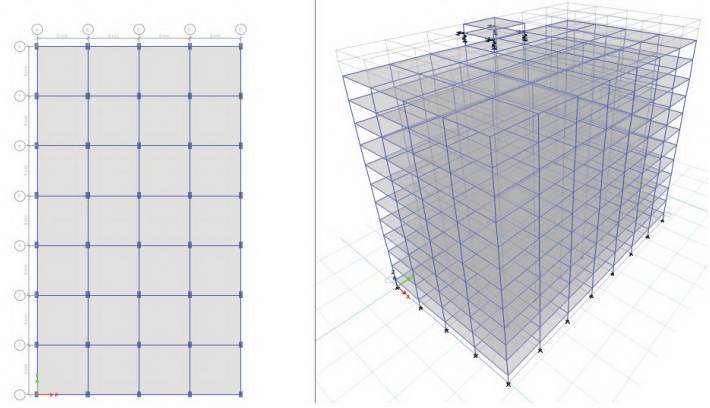

Figure 5. Plan and Isometric view of Model-4 with TLD

\section{SPECIMEN CALCULATIONS}

The Preliminary data for the Analysis of the frame in ETABS is considered as per the prevailing construction practices which is presented below.

1." Type of structure - Moment Resisting Frame

2." Materials - M30, Fe-500

3." Size of Beams - 300x450 mm

4." Size of Columns $-450 \times 750 \mathrm{~mm}$

5." Depth of slab $\quad-150 \mathrm{~mm}$

6." External Wall load - 11.14KN/m (IS 875 Part-1)

7." Internal Wall load - 5.57KN/m (IS 875 Part-1)

8." Seismic zone factor $-0.16 \& 0.24$ (IS 1893:2016)

9." Response Reduction Factor - 5 (IS 1893:2016)

\section{A. Calculations of watertank for Model-1}

Total mass of the structure $=70209.18 \mathrm{KN}$

Water required for single person $=135$ liters

No. of persons in each flat $=5$

No. of flats in the building $=25$

Total no of persons $\quad=125$

Water required $\quad=16875$ Litres

$\begin{array}{ll}\text { Water tank height } & =0.75 \mathrm{~m} \\ \text { Volume of tank } & =\mathrm{LxBxH} \\ \text { Area of tank }(\mathrm{LxB}) & =22.5 \mathrm{~m}^{2} \\ \mathrm{~L} & =6 \mathrm{~m} \\ \mathrm{~B} & =6 \mathrm{~m} \\ \mathrm{H} & =0.75 \mathrm{~m} \\ \text { Total dead load } & =530.82 \mathrm{KN} \\ \text { Live Load (Water Required) } & =165.48 \mathrm{KN} \\ \text { Total water tank load } & =697.05 \mathrm{KN}\end{array}$

B. Calculations of the Tuned Liquid Damper for Model-1

Mass ratio $(\gamma)=\frac{\text { Mass of the water tank }}{\text { Mass of the structure }}$

Natural frequency $\left(\omega_{\mathrm{n}}\right) \quad=1.874 \mathrm{rad} / \mathrm{sec}$

Time period $(\mathrm{Tn})=3.351 \mathrm{sec}$

Tuning ratio $\left(\mathrm{f}_{\mathrm{opt}}\right)=\frac{1}{1+\gamma}$

Optimum damping ratio $\left(\xi_{\text {dopt }}\right)=\sqrt{\frac{3 \gamma}{8(1+\gamma)}}$

Optimum stiffness $\mathrm{K}_{\mathrm{opt}}=\gamma \mathrm{kf}_{\mathrm{opt}}{ }^{2}$

Optimum Damping $\mathrm{C}_{\mathrm{opt}}=2 \omega \mathrm{m} \xi_{\text {dopt }} \gamma$

The above calculations are listed below in Table 1

TABLE I.

CAlculations Of TlmD PARAMETERs For VARying WATER LEVEL IN THE TANK

\begin{tabular}{|c|c|c|c|c|}
\hline & $\begin{array}{c}\text { Empty } \\
\text { Water } \\
\text { tank }\end{array}$ & $\begin{array}{c}\text { One- } \\
\text { third } \\
\text { level } \\
\text { Water }\end{array}$ & $\begin{array}{c}\text { Two- } \\
\text { third } \\
\text { level } \\
\text { water }\end{array}$ & $\begin{array}{c}\text { Full } \\
\text { water } \\
\text { tank }\end{array}$ \\
\hline Mass ratio & 0 & 0.003 & 0.006 & 0.0099 \\
\hline $\begin{array}{c}\text { Tuning } \\
\text { ratio }\end{array}$ & 1 & 0.996 & 0.993 & 0.9901 \\
\hline $\begin{array}{c}\text { Optimum } \\
\text { damping } \\
\text { ratio }\end{array}$ & 0 & 0.035 & 0.049 & 0.0613 \\
\hline $\begin{array}{c}\text { Optimum } \\
\text { stiffness } \\
\text { (KN/m) }\end{array}$ & 0 & 82.72 & 164.37 & 244.94 \\
\hline $\begin{array}{c}\text { Optimum } \\
\text { Damping } \\
\text { (KN-s/m) }\end{array}$ & 0 & 30.74 & 87.09 & 160.26 \\
\hline
\end{tabular}


Responses Of Structure For Model-1 (L-Shape)

Base shear in Zone-III

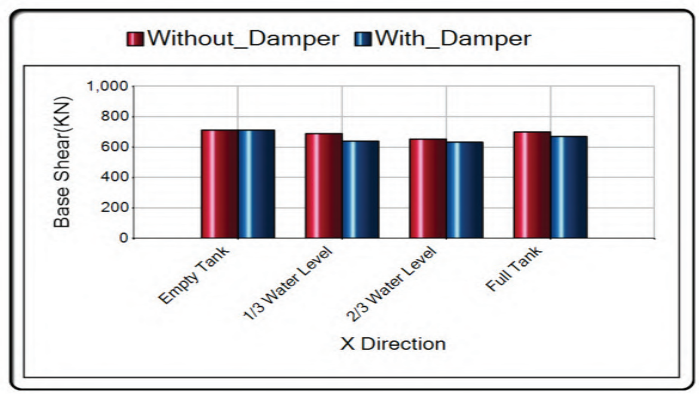

Figure 6. Base shear in Time History Analysis along $\mathrm{X}$ direction

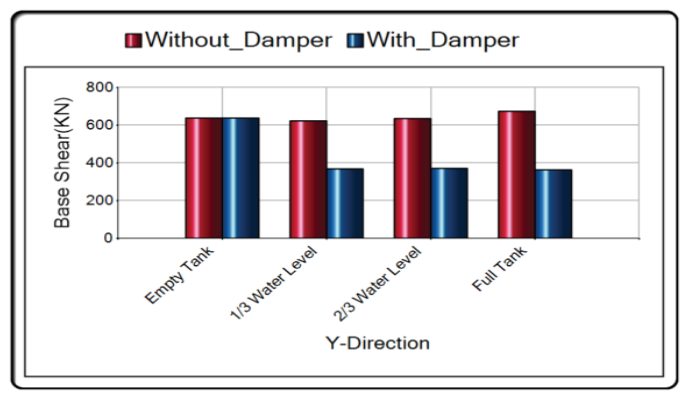

Figure 7. Base shear in Time History Analysis along Y direction

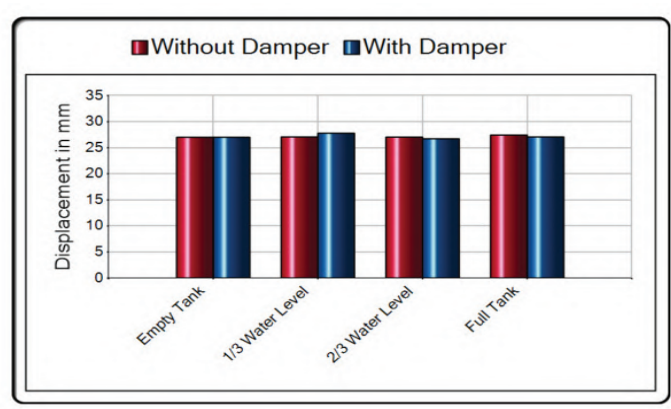

Figure 8. Maximum Storey Displacement in Time History Analysis along X direction

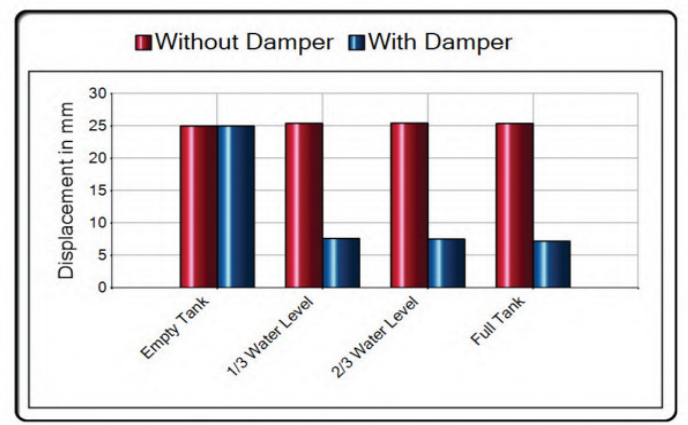

Figure 9. Maximum Storey Displacement in Time History Analysis along Y direction
Responses Of Structure For Model-2 (T-Shape)

Base shear in Zone-III

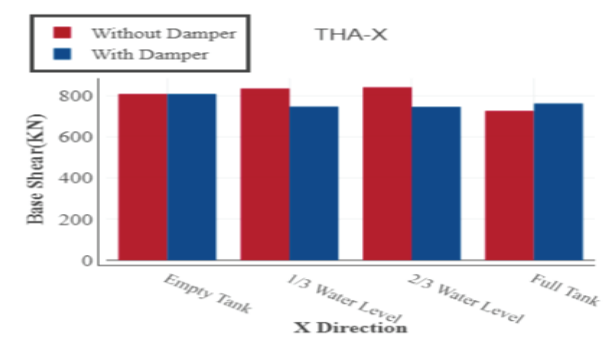

Figure 10. Base shear in Time History Analysis along $\mathrm{X}$ direction

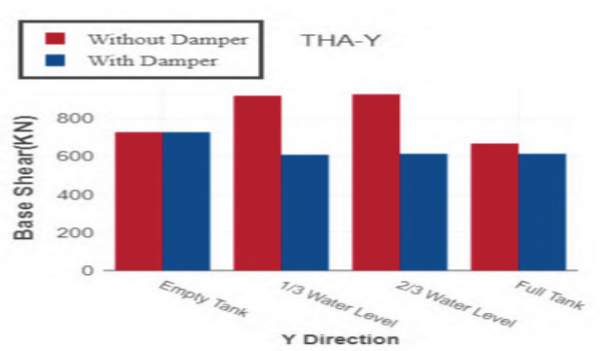

Figure 11. Base shear in Time History Analysis along Y direction

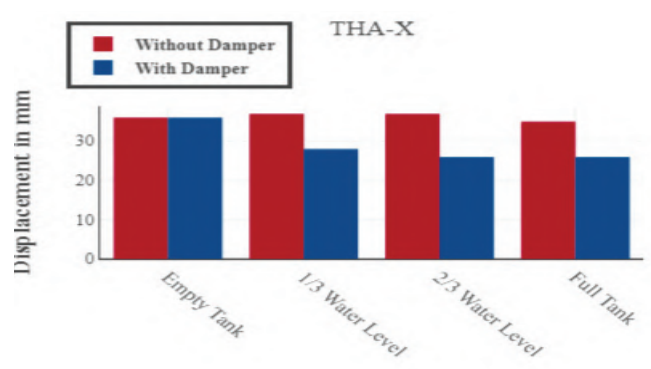

Figure 12. Maximum Storey Displacement in Time History Analysis along X direction

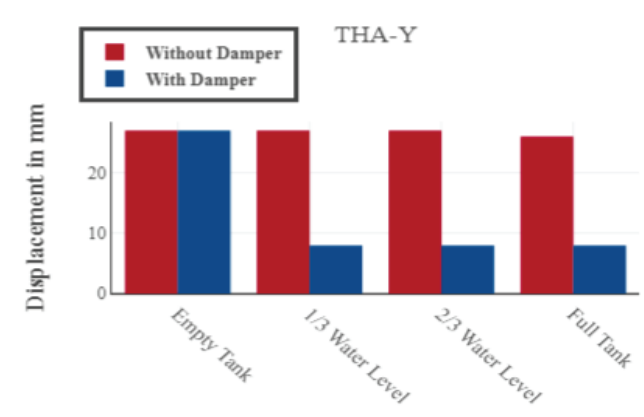

Figure 13. Maximum Storey Displacement in Time History Analysis along Y direction 


\section{RESULTS AND DISCUSSIONS}

The studies are carried-out for water tanks empty, onethird full, two-third full and full tank conditions. The information furnished in Table 2 listed below clearly shows the percentage reduction in the magnitudes of base shear and maximum storey displacements with the utility of the TLD approach. The list of observations reported seperately for zone- 3 and zone- 4 of seismic intensities are as shown below in Table 2.

TABLE II.

Percentage Reduction In The Magnitudes Of Base Shear And MAX DisPlaCEMENTS FROM LINEAR TIME HiSTORY ANALYSIS USING TLD APPROACH

\begin{tabular}{|c|c|c|c|c|}
\hline & \multicolumn{2}{|c|}{ Zone-III } & \multicolumn{2}{c|}{ Zone-IV } \\
\hline PLAN & $\begin{array}{c}\text { Base } \\
\text { shear }\end{array}$ & $\begin{array}{c}\text { Displace } \\
\text { ments }\end{array}$ & $\begin{array}{c}\text { Base } \\
\text { shear }\end{array}$ & $\begin{array}{c}\text { Displac } \\
\text { ements }\end{array}$ \\
\hline $\begin{array}{c}\text { L-shaped } \\
\text { building }\end{array}$ & $46 \%$ & $71 \%$ & $66 \%$ & $83 \%$ \\
\hline $\begin{array}{c}\text { T-shaped } \\
\text { building }\end{array}$ & $8 \%$ & $67 \%$ & $34 \%$ & $68 \%$ \\
\hline $\begin{array}{c}\text { U-shaped } \\
\text { building }\end{array}$ & $40 \%$ & $73 \%$ & $41 \%$ & $74 \%$ \\
\hline $\begin{array}{c}\text { Rectangular } \\
\text { shaped } \\
\text { building }\end{array}$ & $41 \%$ & $35 \%$ & $41 \%$ & $65 \%$ \\
\hline
\end{tabular}

\section{Zone-III}

1." The magnitude of base shear is found to be reduced by $46 \%$ in Y-direction for L-shaped building with the action of Tuned Liquid Mass Damper using Time History method (Figure 7).

2." The Max Storey displacement for Y-direction is found to be reduced by $71 \%$ for L-shaped building with the action of Tuned Liquid Mass Damper using Time History method (Figure 9).

3." The magnitude of base shear is found to be reduced by $8 \%$ for full tank condition in Y-direction for $\mathrm{T}$ shaped building with the action of Tuned Liquid Mass Damper using Time History method (Figure $11)$.

4." The Max Storey displacement for X and Y direction is found to be reduced by $28 \%$ and $67 \%$ respectively for T-shaped building with the action of Tuned Liquid Mass Damper using Time History method (Figure 13).

5." The magnitude of base shear is found to be reduced by $40 \%$ corresponding to with TLD condition in Y direction from for U-shaped building with the action of Tuned Liquid Mass Damper using Time History method

6." The Max Storey displacement for Y-direction is found to be reduced by $73 \%$ for U-shaped building with the action of Tuned Liquid Mass Damper using Time History method.

7." The magnitude of base shear is found to be reduced by $41 \%$ in Y-direction for Rectangular-shaped building with the action of Tuned Liquid Mass Damper using Time History method.

8." The Max Storey displacement for Y-direction is found to be reduced by $35 \%$ for Rectangular shaped building with the action of Tuned Liquid Mass Damper using Time History method.

\section{Zone-IV}

9." The magnitude of base shear is found to be reduced by $66 \%$ in Y-direction for L-shaped building with the action of Tuned Liquid Mass Damper using Time History method.

10." The Max Storey displacement for Y-direction is found to be reduced by $83 \%$ for L-shaped building with the action of Tuned Liquid Mass Damper using Time History method.

11." The magnitude of base shear is found to be reduced by $33.4 \%$ for full tank condition in Y-direction for T-shaped building with the action of Tuned Liquid Mass Damper using Time History method.

12." The Max Storey displacement for $\mathrm{X}$ and $\mathrm{Y}$ direction is found to be reduced by $30 \%$ and $68 \%$ respectively for T-shaped building with the action of Tuned Liquid Mass Damper using Time History method.

13." The magnitude of base shear is found to be reduced by $40.8 \%$ in Y direction for U-shaped building with the action of Tuned Liquid Mass Damper using Time History method.

14." The Max Storey displacement for $\mathrm{X}$ and $\mathrm{Y}$ direction is found to be reduced by $13.6 \%$ and $73.57 \%$ respectively for U-shaped building with the action of Tuned Liquid Mass Damper using Time History method.

15." The magnitude of base shear is found to be reduced by $41 \%$ in Y-direction for Rectangular-shaped building with the action of Tuned Liquid Mass Damper using Time History method.

16."The Max Storey displacement for Y-direction is found to be reduced by $64.8 \%$ for Rectangular shaped building with the action of Tuned Liquid Mass Damper using Time History method.

\section{Conclusions}

The objective of the study is completely achieved by the present study as it can be seen from the list of conclusions. The size of the water tank for the complex is fixed as per the norms of relevant Indian Standards. The quantum of water requirement for each dwelling unit is fixed based on the per capita water requirements as fixed by the local standards.

Based on the studies carried out on different shapes of buildings in different seismic zones, the following conclusions are made:

1. With the introduction of the Tuned Liquid Damper for L-shaped building, the magnitude of base shear and Max storey displacement are found to reduce in about $46 \%$ and $71 \%$ (Figure 7 and Figure 9) respectively in $\mathrm{Y}$-direction (in the direction of weak axis) whereas no 
change is observed in X-direction (Figure 6 and Figure 8).

2. The magnitude of base shear and Max storey displacement is found to reduce in about $10 \%$ and $34 \%$ (Figure 10 and Figure 12) respectively in X-direction and $30 \%$ and $68 \%$ (Figure 11 and Figure 13) respectively in $\mathrm{Y}$-direction (in the direction of weak axis) for T-shaped building when equipped with Tuned Liquid Mass dampers.

3. The magnitude of base shear and Max storey displacement is found to reduce in about $40 \%$ and $73 \%$ respectively in Y-direction (in the direction of weak axis) for U-shaped building when equipped with Tuned Liquid Mass dampers.

4. The magnitude of base shear and Max storey displacement is found to reduce in about $41 \%$ and $65 \%$ respectively in Y-direction (in the direction of weak axis) for Rectangular shaped building when equipped with Tuned Liquid Mass dampers.

5. It is observed that a structure equipped with Tuned Liquid Mass Damper (TLMD) is effective in controlling the the base shear and Maximum storey displacements of the structure when compared to a structure without Tuned Liquid Mass Damper.

Based on the conclusions, the present study clearly demonstrates that there is a substantial reduction of base shear and amplitude of vibration in tall buildings especially in the direction of weak axis, when the overhead water tanks are modelled as Tuned Liquid Mass Dampers.

\section{REFERENCES}

[1]" Mudabbir Imran, Dr. B. K. Raghu prasad "Seismic Response of Tall Structures Using Tuned Mass Dampers", IJREAS (2017)

[2]" A. Lucchini, R. Greco, G. C. Marano and G. Monti "Robust Design of Tuned Mass Damper Systems for Seismic Protection of Multi-storey Buildings", ASCE (2014)

[3]" S.M.Zahrai, A. Ghannadi-Asl "Seismic Performance of TMDs in Improving the Response of MRF Buildings", Scientia Iranica (2008)

[4]" Ashish A. Mohite, G.R. Patil "Earthquake Analysis of Tall Building with Tuned Mass Damper", IOSR (2015)

[5]" Saurabh Chalke, P.V. Muley "Vibration Control of Framed Structure Using Tuned Mass Damper" International Journal of Engineering Development and Research (2017)

[6]" Khemraj S. Deore, Dr. Rajashekhar S. Talikoti, Kanhaiya K. Tolani "Vibration Analysis of Structure using Tuned Mass Damper", International Research Journal of Engineering and Technology (2017)

[7]" Manjusha M, Dr.Vra Saathappan "Analytical Investigation of Water Tank as Tuned Mass Damper Using Etabs", International Research Journal of Engineering and Technology (2017)

[8]" M. J. Tait, N. Isyumov, A. El Damatty "Performance of Tuned Liquid Dampers", ASCE 2008)

[9]" Chidige Anil Kumar, E Arunakanthi "A Seismic Study on Effect of Water Tank modelled as TMD”, International 